\title{
Galanin attenuates the effects of scopolamine but not exposure to a novel environment on acetylcholine release in the rat ventral hippocampus
}

\author{
MATTHEW T. TABER and JACQUELINE N. CRAWLEY \\ National Institute of Mental Health, Bethesda, Maryland
}

\begin{abstract}
In vivo microdialysis was used to measure the effects of galanin on extracellular acetylcholine concentrations in the ventral hippocampus of rats produced by exposure to a novel environment or scopolamine. The novel environment produced a significant increase in acetylcholine release, to $58 \%$ above baseline. This effect was insensitive to pretreatment with galanin ( $5 \mu$ g, i.c.v.) or the peptidergic galanin receptor antagonist M40 (16 $\mu$ g, i.c.v.). In contrast, galanin strongly attenuated the increase in acetylcholine release produced by scopolamine $(0.3 \mathrm{mg} / \mathrm{kg}, \mathrm{s.c}$. $)$. These results indicate that galanin differentially affects the increases in acetylcholine neurotransmission produced by a pharmacological and an environmental stimulus.
\end{abstract}

Evidence from basic and clinical research indicates that the neuropeptide galanin may play an important role in regulating the activity of the basal forebrain cholinergic system, and galanin may be involved in the pathophysiology of Alzheimer's disease (see Crawley, 1996, for review). Postmortem studies of brains of Alzheimer's disease patients reveal an increase in galanin expression in neuronal fibers of the basal forebrain relative to agematched controls (Beal, MacGarvey, \& Swartz, 1990; Chan-Palay, 1988; Mufson, Cochran, Benzing, \& Kordower, 1993). These galanin-containing fibers may originate in interneurons in the basal forebrain or projection neurons from the locus ceruleus, dorsal raphe, or other brain region (Merchanthaler, Lopez, \& Negro-Vilar, 1993). The nucleus basalis of Meynert, a component of the cholinergic basal forebrain, is the site of massive loss of cholinergic cells in Alzheimer's disease, and this loss correlates with the cognitive decline associated with this disorder (Bierer et al., 1995; Coyle, Price, \& Delong, 1983). In humans, galanin and acetylcholine are segregated to separate cell bodies within the basal forebrain, whereas, in rats and some primates, galanin and acetylcholine (ACh) are colocalized in a small percentage of basal forebrain neurons (Benzing, Kordower, \& Mufson, 1993; Melander et al., 1985; Merchanthaler, et al., 1993). In rats and monkeys, galanin has inhibitory actions on evoked ACh release in the ventral but not the dorsal hippocampus (Fisone, Bartfai, Nilsson, \& Hokfelt, 1991; Fisone et al., 1987; Ogren, Kehr, \& Schott, 1996; Robinson, Zocchi, Pert, \& Crawley, 1996). In vivo microdialysis studies show

Correspondence should be addressed to J. N. Crawley, Building 10 , Room 4D11, National Institutes of Health, 9000 Rockville Pike, Bethesda, MD 20892-1375 (e-mail: jncrawle@codon.nih.gov). that increases in ventral hippocampal ACh evoked by systemic scopolamine injection can be strongly attenuated by galanin administered either by intracerebroventricular (i.c.v.) injection (Bartfai et al., 1993; Consolo et al., 1991; Fisone et al., 1991; Robinson et al., 1996) or by direct injection into the medial septum/diagonal band, the component of the basal forebrain cholinergic system that projects primarily to the hippocampus (Robinson et al., 1996). In contrast, galanin alone has no effect on basal ACh concentrations in dorsal or ventral hippocampus in vivo or in vitro (Bartfai et al., 1993; Consolo et al., 1991; Fisone et al., 1991; Fisone et al., 1987). These results have been interpreted as evidence that one function of galanin is to provide a general inhibitory action on ACh release in the ventral hippocampus.

One drawback to this interpretation is that the stimuli employed to evoke galanin release in the experiments described above are nonphysiological stimuli. These stimuli typically produce increases in $\mathrm{ACh}$ on the order of $500 \%-1000 \%$ above baseline (Bartfai et al., 1993; Consolo et al., 1991; Fisone et al., 1991; Robinson et al., 1996). In contrast, stimuli that are more physiologically relevant, such as tone, light, smell, exposure to a novel environment, feeding, drinking, stress, or handling, typically result in increases in ACh release of $50 \%-150 \%$ above baseline (Acquas, Wilson, \& Fibiger, 1996; Inglis \& Fibiger, 1995; Mark, Rada, Pothos, \& Hoebel, 1992; Mark, Rada, \& Shors, 1996; Nilsson, Kalen, Rosengren, \& Bjorklund, 1990). The present experiments tested the hypothesis that galanin would attenuate the increase in extracellular ACh release in the ventral hippocampus produced by exposure to a novel environment. This stimulus was chosen for its ease of use and its robust effects on dorsal hippocampal ACh release (Acquas et al., 1996; Inglis \& Fibiger, 1995). 


\section{METHOD}

All procedures were performed according to the NIH Guidelines for the Care and Use of Animals in Research and approved by the National Institute of Mental Health Animal Care and Use Committee. The subjects were male Wistar rats maintained on a 12:12-h light:dark schedule, and all procedures were performed during the light cycle. The rats were anesthetized with a combination of $x y-$ lazine $(60 \mathrm{mg} / \mathrm{kg}$, i.p.) and ketamine (12 mg/kg, i.p.), and unilateral vertical, concentric-type microdialysis probes (const ructed as described in Nomikos, 1991) were implanted within the ventral hippocampus. Dialysis probes had an active dialysis membrane of $3 \mathrm{~mm}$ (Filtral AN69, Gambro). Ventral tips were implanted, according to the atlas of Paxinos and Watson (1986), as follows: A, $-5.5 \mathrm{~mm}$; $\mathrm{L},-5.0 \mathrm{~mm}$ (relative to bregma); and $\mathrm{V},-7.6$ (relative to dura). Unilateral guide cannulae for intracerebroventricular (i.c.v.) injections were implanted as follows: A, -0.5 ;,-1.0 (relative to bregma); and $V,-3.0$ relative to skull surface. Microinjectors were inserted through the guide and extended an additional $2 \mathrm{~mm}$ such that the tip was located in the left lateral ventricle. The microdialysis probes and guide cannulae were attached to the skull with two screws and dental cement. Following surgery, the rats recovered in their home cages for $24 \mathrm{~h}$, after which they were transferred to a microdialysis chamber in the experimental room. The chamber consisted of a transparent Plexiglas cylinder containing bedding, food, and water; the chamber was $300 \mathrm{~cm}$ tall and $300 \mathrm{~cm}$ in diameter and was placed inside a sound-attenuating enclosure. After overnight habituation to the chamber, microdialysis perfusion began at approximately $8 \mathrm{a} . \mathrm{m}$. the next day.

The microdialysis perfusion solution, containing $\mathrm{NaCl}$ (147 mM), $\mathrm{KCl}(3.0 \mathrm{mM}), \mathrm{CaCl}_{2}(1.3 \mathrm{mM})$, and $\mathrm{MgCl}_{2}(1.0 \mathrm{mM})$ and neostigmine bromide (100 $\mathrm{nM}), \mathrm{pH}=6.3$ (unadjusted), was perfused through the microdialysis probe of the awake, unrestrained rat at $2.0 \mu \mathrm{l} / \mathrm{min}$. Samples were automatically injected (Valco, EC6W ) every 20 min into the sample loop of the HPLC system. Samples were assayed for ACh using HPLC coupled to electrochemical detection according to the method of Damsma, van Beuren, Westerink, and Horn (1987). Briefly, mobile phase, pumped at a rate of $0.35 \mathrm{ml} / \mathrm{min}$ (Model 2200, ESA), carried the dialysate through an analytical column (ACH-1, ESA) and an enzyme reactor (ACH-SPR, ESA) containing acetylcholinesterase and choline oxidase. These enzymes converted the $\mathrm{ACh}$ to peroxide, which was then quantified at a platinum working electrode set at $+300 \mathrm{mV}$ (Model 5040, ESA). The lower limit of this assay was typically about $0.08 \mathrm{pmol} / \mathrm{sample}$.

Samples were collected and assayed for ACh every $20 \mathrm{~min}$, and stable baselines were typically established after $2-3 \mathrm{~h}$. Once baseline was established, the rats received an i.c.v. injection of rat galanin (5 $\mu \mathrm{g}$, Bachem), M40 (galanin-(1-12)-Pro ${ }_{3}$-(Ala-Leu) ${ }_{2}-$ Ala amide; $16 \mu \mathrm{g}$, Bachem), or vehicle (sterile saline) given in a volume of $5 \mu \mathrm{l}$ over $1 \mathrm{~min}$ ( $n=5$ per group). After completion of the injection, the cannula was left in place for an additional $2 \mathrm{~min}$. The injection was timed so that the injection cannula was removed at the end of a 20 -min dialysis sample. Following removal of the microinjector, the subjects either were placed in a novel environment for $20 \mathrm{~min}$ or were given an s.c. injection and returned to their dialysis chambers. The novel environment consisted of an identical cylindrical chamber that contained no food, water, or bedding. The floor was covered with aluminum foil, a novel object was placed in the cage (an empty metal food hopper), and the walls were covered with horizontal black and white stripes $(2.5 \mathrm{~cm}$ wide) two thirds of the way around the cage (to leave a window for observation). The subjects remained in this chamber for $20 \mathrm{~min}$, whereupon they were returned to the microdialysis chamber. The animals receiving s.c. injections were injected with scopolamine $(0.3 \mathrm{mg} / \mathrm{kg}$ ) or vehicle (saline) in a volume of $1 \mathrm{ml} / \mathrm{kg}$ and re- mained in the dialysis chamber for the duration of the experiment ( $n=4$ per group).

To analyze the microdialysis data, $\mathrm{ACh}$ peaks were represented as percentages of baseline, defined as the mean peak height of the four samples immediately preceding the sample containing the i.c.v. injection. Planned comparisons were made with three-way and two-way analysis of variance (ANOVAs), with time as a repeated measure. A probability of .05 was used to judge statistical significance in all cases, and Huynh-Feldt corrections for degrees of freedom were used to account for time as a repeated measure when assessing statistical significance.

During the sample periods prior to and immediately following the i.c.v. or s.c. injection, behavior was assessed by an observer blind to the treatment condition. The rats were scored for the presence of sniffing, locomotion, inactivity, and eating during this time period. Frequency scores for the preinjection and postinjection samples were calculated for each behavior by counting the number of 1-min bins in the session in which the subject was engaged in each behavior. Frequency measures were then converted to percentages and averaged for each group to enable within- and betweensubjects comparisons.

\section{RESULTS}

The mean basal dialysate concentration of $\mathrm{ACh}$ for all subjects was $0.26 \pm 0.02 \mathrm{pmol} / \mathrm{sample}$ (mean $\pm S E M$ ), and no difference was observed between treatment groups $[F(3,12)=1.42, p>.05]$. In 9 rats, tetrodotoxin $(1 \mu \mathrm{M})$ was applied via the microdialysis probe at the end of the experiment, and this treatment resulted in a decrease in acetylcholine concentrations to $<10 \%$ of baseline (data not shown).

Figure 1A shows the effects of exposure to a novel environment following intraventricular injection of galanin, M40, or saline vehicle on extracellular ACh in the ventral hippocampus. The ANOVA performed on these data revealed a significant main effect of time $[F(7,84)=$ $40.7, p<.001]$ but no significant main effect of treatment or treatment $\times$ time interaction. Therefore, exposure to the novel environment increased extracellular ACh concentrations, but neither galanin nor M40 significantly affected these increases.

The effects of galanin on scopolamine-evoked ACh were measured to confirm that galanin was pharmacologically active under the experimental conditions of the present experiment. Figure 1B shows the effects of galanin on scopolamine-induced increases in extracellular $\mathrm{ACh}$. These data were analyzed with a three-way ANOVA containing one within-subjects factor (time) and two betweensubjects factors (galanin [vs. vehicle] and scopolamine [vs. saline]). The ANOVA revealed significant main effects of scopolamine $[F(1,8)=32, p<.001]$ and time $[F(8,96)=12.8, p<.001]$. Significant interactions were observed for time $\times$ galanin $[F(8,96)=11.1, p<.001]$, time $\times$ scopolamine $[F(8,96)=4.6, p<.01]$, and time $\times$ galanin $\times$ scopolamine $[F(8,96)=6.3, p<.01]$. Additional planned comparisons were performed with twoway ANOVAs to assess the effects of galanin within the scopolamine-treated subjects and within the salinetreated subjects. Within the scopolamine-treated rats, a 

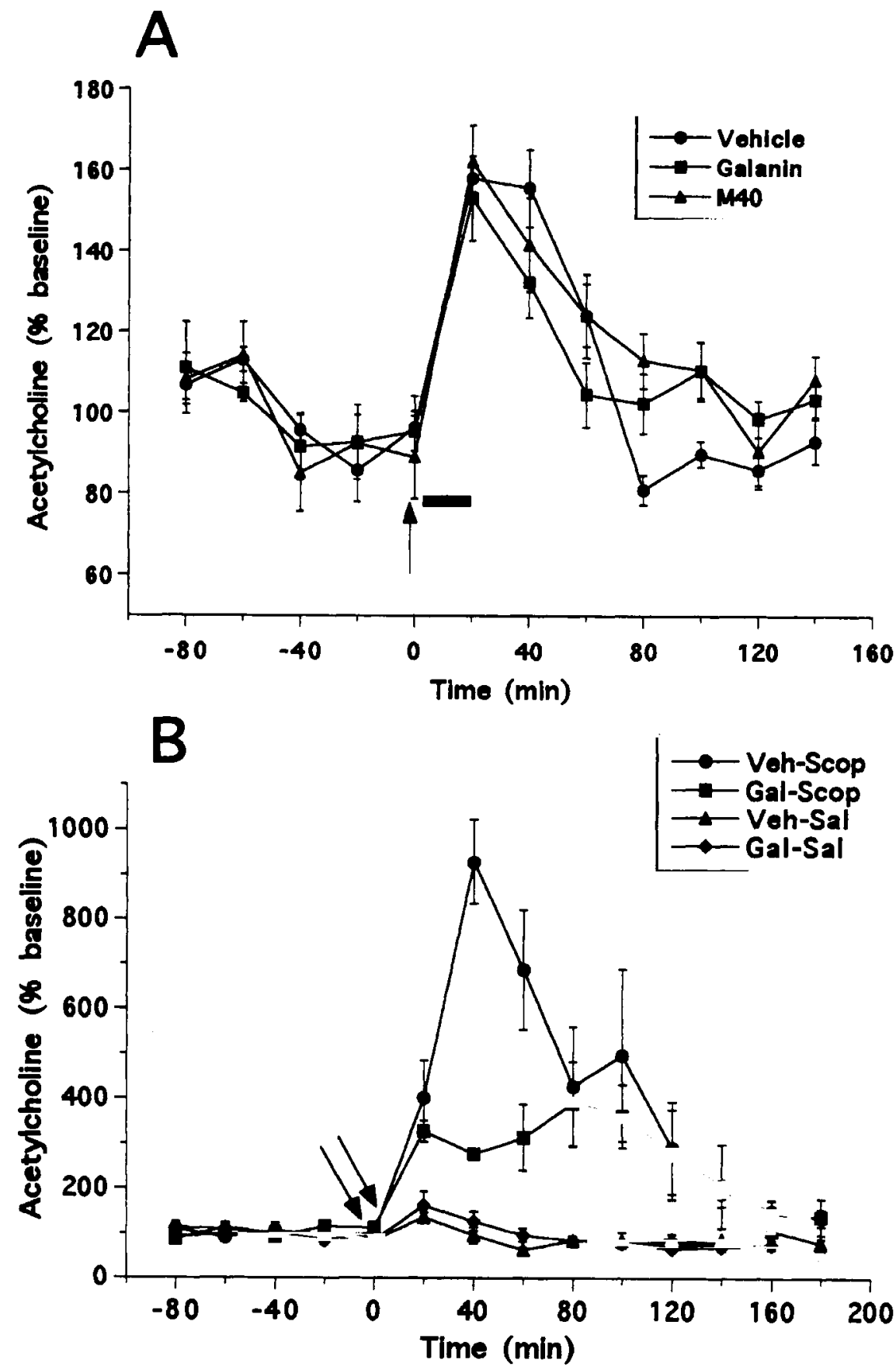

Figure 1. Dialysate concentrations of acetylcholine sampled from the ventral hippocampus of freely moving rats. (A) The arrow indicates the administration of vehicle, galanin (5 $\mu \mathrm{g}$ ), or M40 (16 $\mu$ g); the horizontal bar indicates the period of exposure to the novel environment. Each data point represents the mean $\pm S E M$ for $n=5$ per treatment group. (B) The first arrow indicates administration of vehicle (Veh) or galanin (Gal, $5 \mu \mathrm{g}$ ); the second arrow indicates injection (s.c.) with saline (Sal) or scopolamine (Scop, $0.3 \mathrm{mg} / \mathrm{kg}$ ). Each data point represents the mean $\pm S E M$ for $n=4$ per group.

main effect of time $[F(8,48)=12.2, p<.001]$ and a significant time $\times$ galanin interaction $[F(8,48)=5.6, p<$ $.001]$ were observed. Within the saline-treated rats, a significant main effect of time was observed $[F(8,48)=6.7$, $p<.001]$, but no treatment $\times$ time interaction. These re- sults indicate that saline and scopolamine each produced significant increases in $\mathrm{ACh}$ release, with the effect of scopolamine being significantly greater than that of saline. Furthermore, galanin reduced scopolamine's effects on ACh release but not saline's effects. 
Galanin differently affected changes in behavior produced by the novel environment, scopolamine, and saline. Exposure to the novel environment increased sniffing $[F(1,13)=90.9, p<.0001]$ and locomotion $[F(1,13)=$ $64.3, p<.0001]$ and reduced inactivity $[F(1,13)=139.7$, $p<.0001]$ across time (data not shown). No significant treatment effect or treatment $\times$ time interaction was observed for any behavior, indicating that galanin did not affect the behavioral changes produced by the novel environment. In contrast, galanin reversed the increase in locomotion $[F(1,6)=26.1, p<.01]$ and the decrease in inactivity $[F(1,6)=11.4, p<.01]$ produced by scopolamine. Galanin also increased eating in the saline- and scopolamine-treated rats $[F(1,13)=26.2, p<.001]$.

\section{DISCUSSION}

The present results demonstrate that galanin does not affect the increase in ACh release in the ventral hippocampus produced by exposure to a novel environment under the same conditions in which this neuropeptide strongly reduces the effects of scopolamine. Vehicle injection (saline, s.c.) also significantly increased ACh concentrations in the ventral hippocampus, presumably due to the mild injection stress, and this response was also not affected by galanin application. Galanin produced robust feeding in the saline-treated rats, as previously observed (Crawley et al., 1990), providing evidence that galanin was biologically active under the conditions of the present experiment. These findings indicate that exogenously applied galanin does not have a general inhibitory action on ACh release in the ventral hippocampus.

To examine whether endogenous galanin affected the increase in $\mathrm{ACh}$ produced by exposure to a novel environment, the galanin receptor antagonist M40 was employed. A previous study has found that M40 does not affect basal ACh concentrations in the ventral hippocampus when applied at concentrations that block galanin's effects on scopolamine-evoked ACh release (Bartfai et al., 1993). The present results extend these findings by showing that $\mathrm{M} 40$ (i.c.v.) also does not affect $\mathrm{ACh}$ release produced by exposure to a novel environment. Thus, under these conditions, endogenous galanin does not appear to influence evoked ACh release.

The inability of galanin to affect the small increase in ACh evoked by the novel environment and saline injection seems at odds with galanin's effects on scopolamineevoked ACh release in vivo (e.g., the present results, Consolo et al., 1991; Fisone et al., 1991; Robinson et al., 1996) and potassium-stimulated ACh release in hippocampal slice preparations (Consolo et al., 1991; Fisone et al., 1991; Fisone et al., 1987). One possible explanation for these contrasting results is that galanin attenuates release only when the cholinergic neurons are firing at very high rates, as hypothesized by Hokfelt et al., (1987). Indeed, Consolo et al., (1994) have shown that relatively high frequencies of electrical stimulation of the medial septum are necessary to increase galanin release in the hippocampus. It does not seem likely that $\mathrm{ACh}$ release in the hippocampus triggered by environmental or behavioral stimuli under normal conditions would reach the same level as that produced by scopolamine. Many different environmental, sensory, and behavioral stimuli, including stress, feeding, and handling, produce increases in ACh concentrations in the dorsal hippocampus in the range of $150 \%$ above baseline (Acquas et al., 1996; Inglis \& Fibiger, 1995; Mark et al., 1992; Mark et al., 1996; Nilsson et al., 1990). Performance of a variety of learning tasks, such as operant responding, spontaneous alternation, reinforced alternation, and eyeblink conditioning, also increases $\mathrm{ACh}$ release in the range of $50 \%-150 \%$ above baseline (Fadda, Melis, \& Stancampiano, 1996; Meyer, Allen, \& Yokel, 1996; Orsetti, Casamenti, \& Pepeu, 1996; Ragozzino, Unick, \& Gold, 1996). No environmental stimulus has yet been identified that increases $\mathrm{ACh}$ to the same degree as scopolamine, electrical stimulation, or a high concentration of potassium, which all produce increases in the range of $500 \%-1000 \%$ above baseline.

The comparatively small increase in ACh produced by exposure to the novel environment presents the possibility that this response may have been subject to a "floor" effect. Detecting changes in such a small effect requires greater resolution than does detecting changes in a larger effect, so the variability inherent in the technique could mask an underlying effect. However, in the present results, the variance was quite low in all the novelty-exposed rats, so even a small effect should have been discernible. In fact, the variance in the vehicle + novelty group was comparable to that of the vehicle + scopolamine group when compared as percentages of the amplitude of each effect. In addition, there was no trend toward a reduction in the peak effect of novelty in increasing $\mathrm{ACh}$ release by galanin, so variance probably did not mask any difference. There was a slight numerical trend toward a reduction in ACh at 40 and 50 min postinjection, which suggests that galanin might reduce the duration of the increase in ACh. It remains possible that a higher dose of galanin may be necessary to reduce environmentally stimulated $\mathrm{ACh}$ release than to reduce scopolamine-stimulated $\mathrm{ACh}$ release, due to more complex neural circuitry or other unidentified mechanisms.

Although galanin may not have an important role in regulating ACh release under normal conditions, there are abnormal conditions in which galanin regulation could play an important role. It is possible that, under conditions in which cholinergic neurons are likely to be firing at abnormally high rates, such as in seizure, brain injury, or perhaps Alzheimer's disease, galanin may have an important role in modulating their activity. For example, galanin might be serving some neuroprotective role in conditions of seizure or anoxia, as galanin inhibits glutamate release in the rat hippocampus under such conditions (Ben-Ari \& Lazdunski, 1989; Zini, Roisin, Langel, Bartfai, \& Ben-Ari, 1993). Additionally, in Alzheimer's disease, in which galanin expression is elevated approxi- 
mately twofold in the basal forebrain (Beal et al., 1990; Chan-Palay, 1988; Mufson et al., 1993), galanin levels might then be sufficient to regulate the abnormal $\mathrm{ACh}$ transmission.

In the present experiment, scopolamine increased locomotor activity and decreased inactivity measures, and these effects were significantly reduced by galanin pretreatment. This observation confirms and extends the findings of Robinson et al. (1996), who reported that galanin application in the medial septum/diagonal band also strongly reduced the effects of scopolamine on locomotor activity. However, galanin failed to affect the increase in locomotion or the decrease in inactivity produced by the novel environment, even though these behavioral effects were similar in magnitude to those of scopolamine. These findings indicate that the influence of galanin on scopolamine's behavioral effects is complex and likely involves neuronal circuitry other than or in addition to ventral hippocampal $\mathrm{ACh}$ release. Other mechanisms by which galanin interacts with the effects of scopolamine remain to be characterized.

In summary, the present results confirm and extend the observations that galanin reduces the effects of stimuli, such as scopolamine, electrical stimulation, and a high concentration of potassium, on $\mathrm{ACh}$ release in the ventral hippocampus. However, the present results also indicate that the galanin inhibition of $\mathrm{ACh}$ release does not extend to all stimuli. Whether galanin attenuates the effects of other environmental stimuli on $\mathrm{ACh}$ neurotransmission remains to be determined.

\section{REFERENCES}

Acquas, E., Wilson, C., \& Fibiger, H. C. (1996). Conditioned and unconditioned stimuli increase frontal cortical and hippocampal acetylcholine release: Effects of novelty, habituation, and fear. Journal of Neuroscience, 16, 3089-3096.

Bartfai, T., Langel, U., Bedecs, K., Andell, S., Land, T., Gregersen, S., Ahren, B., Girotti, P., Consolo, S., Corwin, R., CrawLey, J., Xu, X., Wiesenfeld-Hallin, Z., \& Hokfelt, T. (1993). Galanin-receptor ligand $\mathrm{M} 40$ peptide distinguishes between putative galanin-receptor subtypes. Proceedings of the National Academy of Sciences, 90, 11287-11291.

Beal, M. F., MacGarvey, U., \& Swartz, K. J. (1990). Galanin immunoreactivity is increased in the nucleus basalis of Meynert in Alzheimer's disease. Annals of Neuorology, 28, 157-161.

BEN ARI, Y., \& LAZDUNSKI, M. (1989). Galanin protects hippocampal neurons from the functional effects of anoxia. European Journal of Neuroscience, 331-332.

Benzing, W. C., Kordower, J. H., \& Murson, E. J. (1993). Galanin immunoreactivity within the primate basal forebrain: Evolutionary change between monkeys and apes. Journal of Comparative Neurology, 336, 31-39.

Bierer, L. M., Haroutunian, V., Gabriel, S., Knott, P. J., Carlin, L. S., Purohit, D. P., Perl, D. P., Schmeidler, J., Kanof, P., \& Davis, K. L. (1995). Neurochemical correlates of dementia severity in Alzheimer's disease: Relative importance of the cholinergic deficits. Journal of Neurochemistry, 64, 749-60

Chan-PAL.AY, V. (1988). Galanin hyperinnervates surviving neurons of the human basal nucleus of Meynert in dementias of Alzheimer's and Parkinson's disease: A hypothesis for the role of galanin in accentuating cholinergic dysfunction in dementia. Journal of Comparative Neurology, 273, 543-557.

Consolo, S., Baldi, G., Russi, G., Civenni, G., Bartfai, T., \& Vez-
ZANI, A. (1994). Impulse flow dependency of galanin release in vivo in the rat ventral hippocampus. Proceedings of the National Academy of Sciences, 91, 8047-8051.

Consolo, S., Bertorelli, R., Girotto, P., La Porta, C., Bartfai, T., Parenti, M., \& Zambelli, M. (1991). Pertussis toxin sensitive Gprotein mediates galanin's inhibition of scopolamine-evoked acetylcholine release in vivo and carbachol-stimulated phosphoinositide turnover in rat ventral hippocampus. Neuroscience Letters, 126, 29 32.

Coyle, J. T., Price, D. L., \& Delong, M. (1983). Alzheimer's disease A disorder of cholinergic innervation. Science, 219, 1184-1190.

Crawley, J. N. (1996). Galanin-acetylcholine interactions: Relevance to memory and Alzheimer's disease. Life Sciences, 58, 2185-2189.

Crawley, J. N., Austin, M. C., Fiske, S. M., Martin, B., Consolo, S., Berthold, M., Langel, U., Fisone, G., \& Bartfai, T. (1990). Activity of centrally administered galanin fragments on stimulation of feeding behavior and galanin receptor binding in the rat hypothalamus. Journal of Neuroscience, 10, 3695-3700.

Damsma, G., van Beuren, L., Westerink, B. H. C., \& Horn, A. S. (1987). Determination of acetylcholine and choline in the femtomole range by means of HPLC, a post column enzyme reactor, and electrochemical detection. Chromatographia, 24, 827-831.

Fadda, F., MElis, F., \& Stancampiano, R. (1996). Increased hippocampal acetylcholine release during a working memory task. European Journal of Pharmacology, 307, R1-R2.

Fisone, G., Bartfai, T., Nilsson, S., \& Hokfelt, T. (1991). Galanin inhibits the potassium-evoked release of acetylcholine and the muscarinic receptor-mediated stimulation of phosphoinositide turnover in slices of monkey hippocampus. Brain Research, 568, 279-284.

Fisone, G., Chun, C. F., Consolo, S., Nordstrom, O., Brynne, N., Bartfal, T., Melander, T., \& Hokfelt, T. (1987). Galanin inhibits acetylcholine release in the ventral hippocampus of the rat: Histochemical, autoradiographic, in vivo, and in vitro studies. Proceedings of the National Academy of Sciences, 84, 7339-7343.

hokfelt, T., Millhorn, D., Seroogy, K., Tsururo, Y., Cecatelli, S., Lindh, B., Meister, B., Melander, T., Schalling, M., BartFAI, T., \& Terenius, L. (1987). Coexistence of peptides with classical neurotransmitters. Experientia, 43, 768-780.

INGLIS, F. M., \& Fibiger, H. C. (1995). Increases in hippocampal and frontal cortical acetylcholine release associated with presentation of sensory stimuli, drinking. Neuroscience, 66, 81-86.

Mark, G. P., Rada, P., Pothos, E., \& Hoebel, B. G. (1992). Effects of feeding and on acetylcholine release in the nucleus accumbens, striatum, and hippocampus of freely behaving rat. Journal of Neurochemistry, 58, 2269-2274.

MARK, G. P., RADA, P. V., \& Shors, T. J. (1996). Inescapable stress enhances extracellular acetylcholine in the rat hippocampus and prefrontal cortex but not the nucleus accumbens or amygdala. Neuroscience, 74, 767-774.

Melander, T., Staines, W. A., Hokfelt, T., Rokaeus, A., EckenStein, F., Salavaterra, P. M., \& Wainer, B. H. (1985). Galaninlike immunoreactivity in cholinergic neurons of the septum-basal forebrain complex projecting to the hippocampus of the rat. Neuroscience, 19, 223-240.

Merchanthaler, I., Lopez, F. J., \& Negro-Vilar, A. (1993) Anatomy and physiology of central galanin containing pathways. Progress in Neurobiology, 40, $711-769$.

Meyer, J. J., Allen, D. D., \& Yokel, R. A. (1996). Hippocampal acetylcholine increases during eyeblink conditioning in the rabbit. Physiology \& Behavior, 60, 1199-1203.

Mufson, E. J., Cochran, E., Benzing, W., \& Kordower, J. H. (1993) Galaninergic innervation of the cholinergic vertical limb of the diagonal band ( $\mathrm{Ch} 2$ ) and bed nucleus of the stria terminalis in aging, Alzheimer's disease, and Down's syndrome. Dementia, 4, 237-250.

Nilsson, O. G., Kalen, P., Rosengren, E., \& Bjorklund, A. (1990). Acetylcholine release in the rat hippocampus as studied by microdialysis is dependent on axonal impulse flow and increases during behavioral activation. Neuroscience, 36, 325-338.

Nomikos, G. G. (1991). In vivo neurochemical effects of antidepressant treatments studied by microdialysis. Unpublished doctoral thesis, University of British Columbia. 
Ogren, S. O., Kehr, J., \& SchotT, P. A. (1996). Effects of ventral hippocampal galanin on spatial learning and in vivo acetylcholine release in the rat. Neuroscience, 75, 1127-1140.

Orsetti, M., Casamenti, F., \& Pepeu, G. (1996). Enhanced acetylcholine release in the hippocampus and cortex during acquisition of an operant behavior. Brain Research, 724, 89-96.

Paxinos, G., \& Watson, C. (1986). The rat brain in stereotaxic coordinates (2nd ed.). San Diego: Academic Press.

Ragozzino, M. E., Unick, K., \& Gold, P. E. (1996). Hippocampal acetylcholine release during memory testing in rats: Augmentation by glucose. Proceedings of the National Academy of Sciences, 93, 4693-4698.
Robinson, J. K., Zocchi, A., Pert, A., \& Crawley, J. N. (1996). Galanin microinjected into the medial septum inhibits scopolamineinduced acetylcholine overflow in the rat ventral hippocampus. Brain Research, 709, 81-87.

Zini, S., Roisin, M.-P., Langel, U., Bartfal, T., \& Ben-ARI, Y. (1993). Galanin reduces release of endogenous excitatory amino acids in the rat hippocampus. European Journal of Pharmacology, 245, 1-7.

(Manuscript received January 9, 1998; revision accepted for publication April 23, 1998.) 